\title{
Vocational intervention in first-episode psychosis: individual placement and support $v$. treatment as usual
}

\author{
Eóin Killackey, Henry J. Jackson and Patrick D. McGorry
}

\section{Background}

Unemployment is a major problem for people with firstepisode psychosis and schizophrenia. This has repercussions for the economy, social functioning and illness prognosis.

\section{Aims}

To examine whether a vocational intervention - individual placement and support (IPS) - which has been found to be beneficial in populations with chronic schizophrenia, was a useful intervention for those with first-episode psychosis.

\section{Method}

A total of 41 people with first-episode psychosis were randomised to receive either 6 months of IPS + treatment as usual (TAU) $(n=20)$ or TAU alone $(n=21)$.

\section{Results}

The IPS group had significantly better outcomes on level of employment (13 v. 2, $P<0.001)$, hours worked per week (median 38 v. 22.5, $P=0.006$ ), jobs acquired ( 23 v. 3) and longevity of employment (median 5 weeks $v$. $0, P=0.021$ ). The IPS group also significantly reduced their reliance on welfare benefits.

\section{Conclusions}

Individual placement and support has good potential to address the problem of vocational outcome in people with first-episode psychosis. This has economic, social and health implications.

\section{Declaration of interest}

This research was supported by a National Health and Medical Research Council Program Grant (ID: 350241) and an unrestricted study grant from Bristol Myers Squibb. ORYGEN Research Centre is supported by the Colonial Foundation.
A key problem facing people with psychotic illnesses is unemployment. ${ }^{1}$ This is despite surveys consistently showing that gaining a job in open employment is a primary goal of most people with mental illnesses. ${ }^{2}$ Unemployment is the largest contributor to indirect costs of psychotic illnesses. ${ }^{3,4}$ In response to this problem, a method of vocational intervention called 'individual placement and support' (IPS) has been developed. This highly defined form of supported employment has proven, through a number of randomised controlled trials, to be an effective intervention for people with chronic mental illness. ${ }^{5}$ However, there have been no published randomised controlled trials of this approach in those with first-episode psychosis, a group who also have high levels of unemployment and who are normally in a phase of life where vocational development typically occurs. This study aimed to examine the effectiveness of IPS in a group of young people with first-episode psychosis who wanted to find work.

\section{Method}

\section{Participants}

Between October 2005 and April 2006, 41 people who were attending a specialist public mental health service and who wanted help in finding work were recruited to the study. All were patients of the Early Psychosis Prevention and Intervention Centre (EPPIC) in Melbourne, Australia. This service treats all cases of a first-episode of psychosis in people aged between 15 and 25 years living in a defined catchment area of about 1 million people. Within this catchment area, the number of people aged 15-25 years is estimated to be 250000

Individuals were eligible for the study if they wanted to find work (including a different job if they currently held one) and had at least 6 months of care left at EPPIC (EPPIC is limited to providing 18 months of care). The only exclusion criterion was lack of fluency in English. Nobody needed to be excluded on this basis.

Informed consent was required to participate in the study, and decisions regarding participation did not influence clinical care in any way. Participants were recruited via EPPIC case managers identifying people from their case-load who were interested in seeking work. There were no refusers. Assessments were conducted by an experienced, trained research assistant who was also an advanced psychology doctoral student. Assessments were generally conducted at EPPIC but some were also completed in participants' homes.

\section{Interventions}

In this study, IPS + treatment as usual (TAU) (the vocationalintervention group) was compared with TAU alone as there is no established evidence-based vocational intervention for those with first-episode psychosis. Treatment as usual consisted of participants continuing to receive EPPIC care. This involves individual case management and medical review, referral to external vocational agencies, as well as involvement with the group programme at EPPIC, which may involve participation in the vocationally oriented groups within the group programme. Treatment as usual was delivered primarily by EPPIC case managers.

Individual placement and support is a highly defined form of supported employment and has six key principles:

(a) it is focused on competitive employment (i.e. jobs which are not set aside but open to applications from anyone with the appropriate skills or qualifications) as an outcome;

(b) it is open to any person with mental illness who chooses to look for work and acceptance into the programme is not determined by measures of work-readiness or illness variables; 
(c) job searching commences directly on entry into the programme;

(d) the IPS programme is integrated with the mental health treatment team;

(e) potential jobs are chosen based on consumer preference;

(f) the support provided in the programme is time-unlimited, continuing after employment is obtained, and is adapted to the needs of the individual. ${ }^{6}$

A seventh principle, also sometimes considered as part of the model of IPS, is welfare benefits counselling, ${ }^{7}$ as there are often disincentives to be negotiated in the transition from a welfare benefit to paid employment. ${ }^{1,8}$ These can include loss of concessions for transport and utilities, high effective marginal tax rates and loss of public health access. Strong evidence supports the first four of the seven IPS principles as being necessary to successful implementation of the model. ${ }^{7}$ The other three principles have only weak evidence to support their inclusion. ${ }^{7}$ In the present trial, this vocational intervention was delivered by an employment consultant employed for the project. ${ }^{9}$ She was co-located with the clinical team and attended clinical review meetings. She delivered the intervention both on-site and off-site, and via phone calls. Location and frequency of service delivery was based on individual needs.

\section{Objectives}

The objectives of this study were to compare the effectiveness of vocational intervention with a control condition of TAU in helping people with first-episode psychosis find work or enter a course congruent with their career aims. It explored the following hypotheses:

(a) that those in the vocational-intervention group would have better outcomes (defined as employment or enrolment in a course) within 6 months than those in the TAU group;

(b) that people in the intervention group would obtain more jobs than those in the TAU group;

(c) that people in the intervention group would work more weeks and earn more money than those in the TAU group;

(d) that those in the intervention group would use welfare benefits less than those in the TAU group.

\section{Outcomes}

As this study was concerned only with the effectiveness of IPS as a vocational intervention, and as there is little evidence in the literature of vocational outcomes having an effect on symptom outcomes, the primary outcomes reported here are numbers of jobs and courses, longevity of work, money earned and level of access to welfare benefits. Secondary outcomes which are beyond the scope of this report would be the effect of employment on symptoms and quality of life domains.

\section{Measures}

In both groups assessment occurred at baseline and at 6 months, following the conclusion of the intervention in the intervention group. Assessment at both times covered a number of demographic, symptom, diagnostic and functioning areas as detailed below.

\section{Baseline descriptive measures}

Demographic data included age, gender, employment and educational history, length of illness, medication dosage and adherence, living situation, marital status, current employment status and welfare benefit status.

The Brief Psychiatric Rating Scale ${ }^{10}$ was used to measure the presence and severity of psychopathology during the previous 2 weeks. Negative symptoms were assessed by the Scale for the Assessment of Negative Symptoms. ${ }^{11}$ Depression was measured by the Center for Epidemiologic Studies Depression Scale-Revised. ${ }^{12}$

Diagnoses were reached by means of the Structured Clinical Interview for DSM-IV-TR Axis 1 Disorders - Patient Edition $(\mathrm{SCID}-\mathrm{I} / \mathrm{P}){ }^{13}$

Two measures were used to assess functioning. The first was the Quality of Life Scale ${ }^{14}$ - a 21-item semi-structured interview which provides a total score comprised of four sub-scales: intrapsychic foundations, interpersonal relations, instrumental role, and common objects and activities. Only the total score is reported in this paper. The second measure used to assess functioning was the Social and Occupational Functioning Assessment Scale (SOFAS). ${ }^{15}$ The SOFAS is a 100 -point single-item scale in which the assessor rates the individual according to their lowest level of functioning in the past month. Scores range from 0 to 100 with 100 indicating superior functioning in a wide range of activities, and lower scores indicating lower levels of functioning. The SOFAS score is indicative of social and occupational functioning and does not take into account level of psychopathology.

\section{Primary outcome measures}

The primary outcome measures in this project were: the number of jobs a participant had held in the intervention period; the hourly rate of pay and the number of hours worked per week; the number of weeks in each job or in their current job at the time of follow-up; the number of courses that a participant had completed or was currently enrolled on at the time of followup; and welfare benefit receipt status.

\section{Fidelity measures}

The Supported Employment Fidelity Scale-Implementation Questions ${ }^{16}$ was used to assess the fidelity of the programme to the IPS model. This was assessed by E.K. (and reviewed with an interstate colleague independent of the project from the only other research group working in this area in Australia) by using existing knowledge of the programme parameters and by direct observation of the clinical team and the employment consultant.

\section{Sample size}

Sample size was determined by pragmatic considerations as there were no previous randomised studies of vocational interventions in this population to guide us. In the end, 41 people were recruited. There were 20 people in the intervention group and 21 in the TAU group. One person dropped out from the intervention group and 5 from the TAU group (Fig. 1). Four people from the TAU group dropped out because they had enrolled wanting help to find work and felt that as they were not getting it they no longer wished to continue in the project. The remaining two people (one in each group) dropped out as they were sent to jail for offences that occurred before their enrolment in the trial. However, all who dropped out gave their permission for their employment status at follow-up to be determined from their case manager and medical records.

\section{Randomisation}

Participants were randomised by a statistician independent of the study using computer-generated random numbers to carry out 


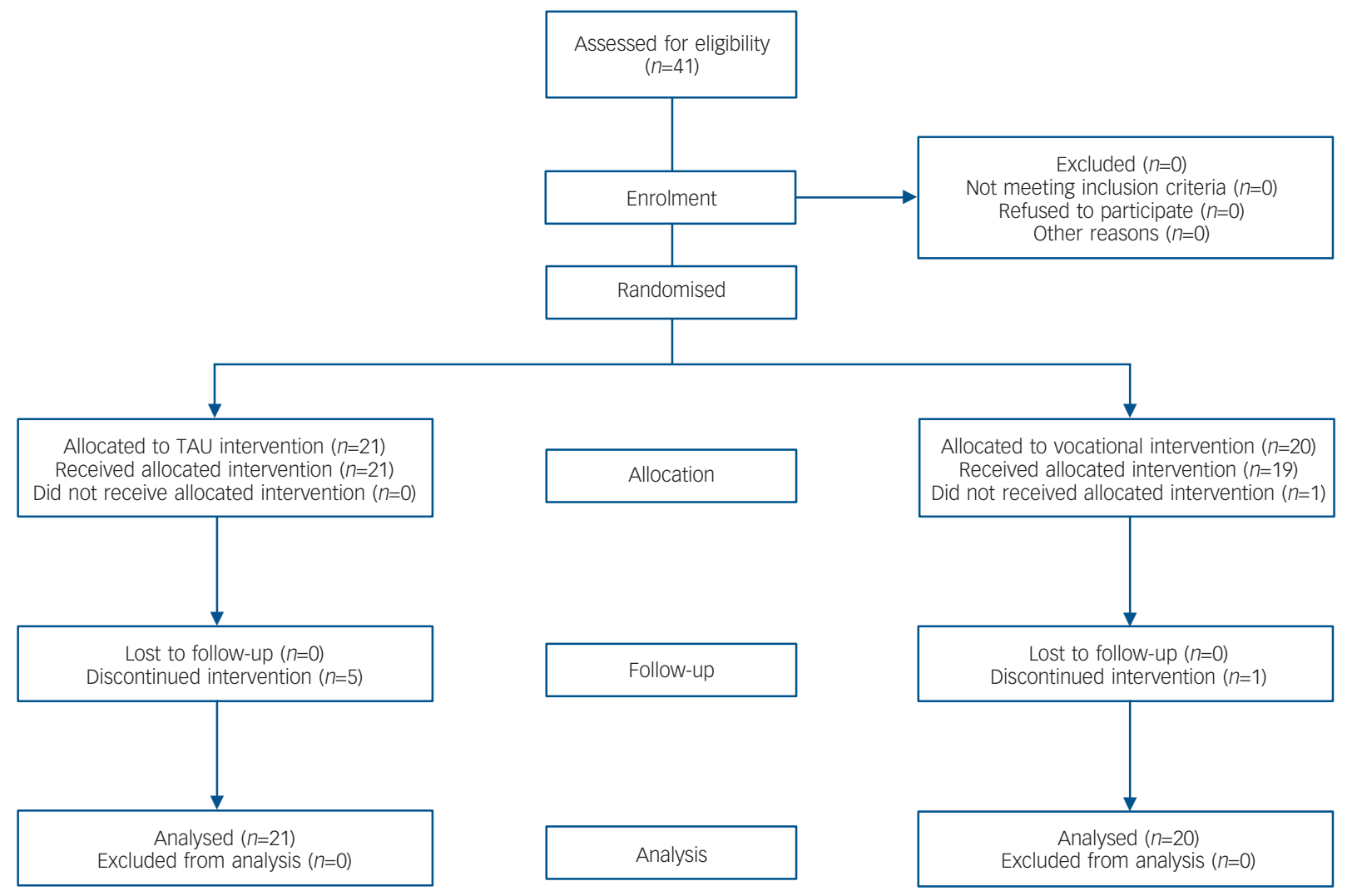

Fig. 1 Flow diagram of study participants. TAU, treatment as usual.

blocked randomisation to one of the two conditions. The statistician would be contacted by the leader of the project (E.K.) when a new participant enrolled and the statistician would inform E.K. of the group allocation. This information would then be given to the participant, the case manager of the participant and also the employment consultant if allocation was to the intervention group. The research assistant was not involved in this process, but there were no formal tests of her masking to allocation.

\section{Statistical methods}

Statistical analysis was conducted using SPSS version 14.0 for Windows. Group differences were calculated using independentsamples $t$-tests and chi-squared analysis. Logistic regressions were conducted to ensure that differences observed in main outcome variables were related to group membership rather than variables that were different at baseline.

\section{Results}

\section{Baseline data}

There were no significant differences between the groups on most of the demographic or symptom variables at baseline (Table 1). There was a difference in marital status. As more people in the TAU group were in marital or marital-like relationships, this would tend to bias the study against finding success for the vocational intervention, as people in marital relationships tend to function better socially and in employment. ${ }^{17}$ There was a significant difference between the groups on the SOFAS, with the TAU group having a higher SOFAS score than the intervention group. This again would bias the study against the success of the intervention group. Importantly, there were no differences between groups in either medication levels or self-reported medication adherence. All participants were patients of a specialised public first-episode psychosis service and had received clinical diagnoses of schizophrenia-spectrum disorders. On assessment with the SCID-I/P, in addition to their primary psychotic disorders, all but 5 had other comorbid disorders: 20 had a mood diagnosis, 1 had a pervasive developmental disorder, 3 had anxiety diagnoses, 23 had substance use diagnoses and 7 had other diagnoses.

At baseline, 1 person in the intervention group was working in a part-time job and 2 people in the TAU group were working, 1 full-time and 1 part-time.

\section{Dosing of the intervention}

On average, the employment consultant had 29.55 (s.d.=11.45) contacts with each participant in the intervention group across the 6-month intervention. Of these, most (19.3) were by telephone and the others were split evenly between in-office (5.05) and outof-office (5.2) contacts. Total number of contacts was significantly correlated with number of job interviews $(r=0.511, P=0.025)$; number of job interviews was correlated with employment outcome ( $r=0.347, P=0.044)$. On average, those in the intervention group had 3.00 (s.d.=4.72) job interviews, compared with 1.47 (s.d.=2.77) for those in the TAU group. Ten of the participants in the TAU group used an external employment agency. None of these obtained work during the period of the trial. There was no evidence of a cumulative time effect of the intervention for those in the intervention group. Of the 13 who found employment, 3 worked for more than 20 of a possible 26 weeks, 5 worked 


\begin{tabular}{|c|c|c|c|}
\hline Variable & Treatment-as-usual group & Vocational-intervention group & Significance \\
\hline Age, years & $21.42(2.21)$ & $21.29(2.39)$ & NS \\
\hline Gender, male/female & $17 / 4$ & $16 / 4$ & NS \\
\hline Age at onset, years & $20.47(2.61)$ & $19.95(2.93)$ & NS \\
\hline Length of illness, months & $12.25(12.98)$ & $15.68(14.17)$ & NS \\
\hline Time at EPPIC, months & $8.89(12.88)$ & $9.55(8.30)$ & NS \\
\hline \multicolumn{4}{|l|}{ Marital status, $n$} \\
\hline Married/defacto & 7 & 1 & \multirow[t]{2}{*}{$P=0.002$} \\
\hline Never married & 10 & 19 & \\
\hline \multicolumn{4}{|c|}{ Education (highest level achieved), $n$} \\
\hline Year 7 & 1 & 1 & \multirow[t]{6}{*}{ NS } \\
\hline Year 8 & 0 & 4 & \\
\hline Year 9 & 4 & 3 & \\
\hline Year 10 & 4 & 6 & \\
\hline Year 11 & 1 & 1 & \\
\hline Year 12 & 7 & 4 & \\
\hline \multicolumn{4}{|l|}{ English, $n$} \\
\hline Poor & 0 & 0 & \multirow[t]{4}{*}{ NS } \\
\hline Fair & 0 & 0 & \\
\hline Good & 1 & 2 & \\
\hline Native language & 16 & 17 & \\
\hline SOFAS & 57.35 (10.39) & 49.79 (10.53) & $P=0.037$ \\
\hline Medication, $\mathrm{mg}^{\mathrm{b}}$ & 281.25 (113.98) & 347.66 (135.42) & NS \\
\hline BPRS & $34.12(8.10)$ & $37.00(8.7)$ & NS \\
\hline CESD-R & $18.81(11.64)$ & 20.94 (15.05) & NS \\
\hline SANS & $18.47(14.27)$ & $26.58(16.84)$ & NS \\
\hline $\mathrm{QOL}$ & 78.35 (18.74) & 72.21 (13.95) & NS \\
\hline \multicolumn{4}{|c|}{$\begin{array}{l}\text { BPRS, Brief Psychiatric Rating Scale; CESD-R, Center for Epidemiologic Studies Depression scale-Revised; EPPIC, Early Psychosis Prevention and Intervention Centre; NS, no } \\
\text { significant; QOL, Quality of Life scale; ;ANS, Scale for the Assessment of Negative Symptoms; SOFAS, Social and Occupational Functioning Assessment Scale. } \\
\text { a. Values shown as mean (s.d.) unless otherwise indicated. } \\
\text { b. Chlorpromazine equivalent. }\end{array}$} \\
\hline
\end{tabular}

for between 10 and 20 weeks, and 5 worked between 1 and 10 weeks.

\section{Fidelity of the intervention}

Scoring the intervention in consultation with an independent researcher using the Supported Employment Fidelity ScaleImplementation Questions ${ }^{16}$ indicated that the intervention was carried out with high fidelity $(68 / 75)$.

\section{Overall outcome}

The primary outcome of this study was whether or not young people with first-episode psychosis who wished to find work were helped in their vocational pursuits through access to an IPS programme with high fidelity to the IPS model. Overall, 13 of 20 people in the intervention group found employment compared with 2 of 21 in the TAU group. In each group, 4 people enrolled in courses but did not find employment. Of those who found work, 3 in the intervention group and 1 in the TAU group also enrolled in courses. Results of individual hypotheses will now be reported.

\section{Hypotheses testing}

Hypothesis one

In the vocational-intervention group, 17 out of 20 people either had found a job, enrolled in a course or did both, compared with 6 out 21 in the TAU group $\left(\chi^{2}(1)=13.24, P<0.001\right)$ (Fig. 2$)$. When only employment was considered as an outcome, the difference was still significant $\left(\chi^{2}(1)=13.59, P<0.001\right.$ (TAU $2 / 21 v$. intervention 13/20)) (Fig. 3).

A range of jobs were undertaken by those who found work in this project. In the vocational-intervention group this included: meat/chicken factory process worker, sandblasting labourer, apprentice panel beater, factory hand (data dotting), nursery hand (sprout picking), vehicle dismantling trade assistant, meat packing, warehouse order picker, service personnel, bricklayer, factory hand, recruitment agency resourcer, tyre fitter, landscaping labourer, chemical processor, bar attendant, call-centre operator, website developer, product stocker and apprentice hairdresser.

Courses undertaken were in keeping with vocational objectives. Participants were supported by the employment consultant as though they were in a job (and courses were often for a licence or certificate for employment required in the participant's desired area of work). Courses included forklift licence training; occupational health and safety; responsible service of alcohol; first-aid; secondary school classes; degree in screen printing; and diploma in cleaning.

In the TAU group, only two participants gained employment during the study. One worked for only 1 week (in a labouring job) and the other worked for the entire period of the study (in two jobs which were concurrent for 5 weeks at one stage, thus giving him 31 weeks of employment in a 26 -week period; Table 2). In addition, this person also held a third job on entry into the study.

\section{Hypothesis two}

Those in the intervention group were able to find more jobs than those in the TAU group: 23 jobs $v .3$ jobs respectively, were 


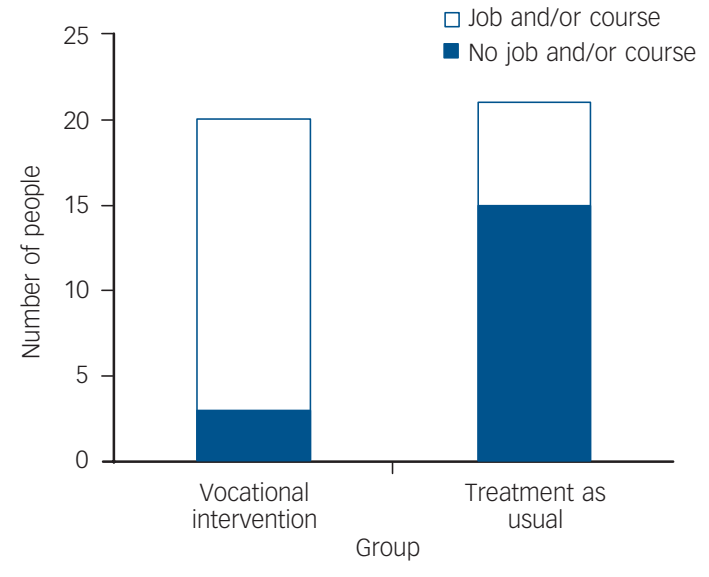

Fig. 2 Employment and enrolment status by group.

obtained over the intervention period (Mann-Whitney $U$-test: $Z=-2.964, P=0.006)$.

\section{Hypothesis three}

As can be seen in Table 2, people in the intervention group worked more weeks and earned more money overall than those in the TAU group. They also had more hours per week in those jobs. Because of the low number in the TAU group who earned any income, the effect is not seen in the dollars per hour result.

\section{Hypothesis four}

At baseline, $80 \%$ of the intervention group listed welfare benefits as their primary source of income, compared with $57.1 \%$ of people in the TAU group. At the end of the intervention, there had been a reduction of $25 \%$ to $55 \%$ of people with benefits as their primary income in the intervention group, compared with a $0 \%$ decrease in the TAU group. Two separate Cochran's Q-tests were conducted to determine whether there was significant change in use of benefits within the TAU and intervention groups. The change in use of benefits was not significant for the TAU group (c2(1)=1.0, $P=0.317$ ); however, there was significant change in the intervention group $(\mathrm{c} 2(1)=5.0, P=0.025)$.

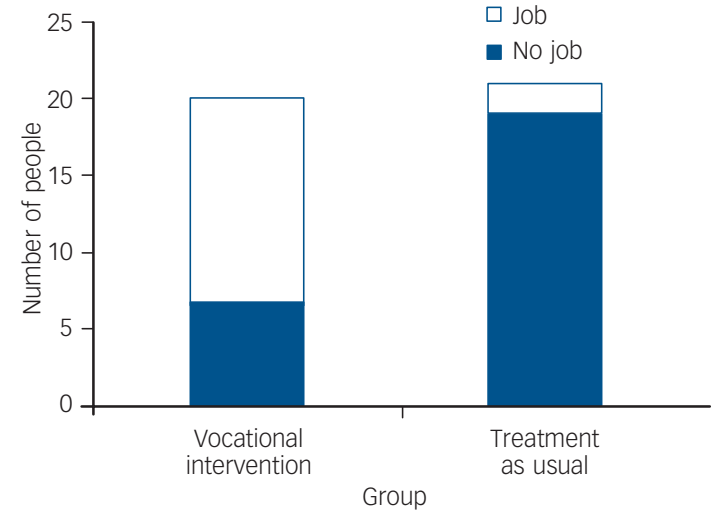

Fig. 3 Employment status by group.

\section{Regression analyses}

In order to ensure that the variables which were different between the groups at baseline (SOFAS score and marital status) were not responsible for the difference in outcomes between groups, regression analyses were carried out. In the first regression, enrolment in a course or a job was the dependent variable, and SOFAS and marital status were independent variables. In the second, employment alone was the dependent variable and the same independent variables were used. Marital status and SOFAS score were entered before group (intervention or TAU). In the first step of the first regression, neither marital status $(P=0.051)$ nor SOFAS score $(P=0.536)$ was significant. When group was added, SOFAS became significant $(P=0.023, \mathrm{OR}=1.179)$, group was significant $(P=0.005, \mathrm{OR}=260.658)$ and marital status was not significant $(P=0.421)$. The model with only marital status and SOFAS score had an $r^{2}=0.10$. With group included, the proportion of variance explained increased from $10.49 \%$ to $43.51 \%$.

The results followed a similar pattern for employment only as an outcome. In the first step, neither SOFAS score $(P=0.267)$ nor marital status $(P=0.156)$ was significant. In the second step, group $(P=0.007, \mathrm{OR}=4202.088)$ and SOFAS score $(P=0.006, \mathrm{OR}=1.270)$ were significant. The model with only marital status and SOFAS score had $r^{2}=0.08$. With group included, the proportion of variance explained increased from $8 \%$ to $56.21 \%$.

\begin{tabular}{|c|c|c|c|c|}
\hline & Mean (s.d.) & Median & Maximum & Minimum \\
\hline \multicolumn{5}{|l|}{ Weeks worked, $n$} \\
\hline Treatment as usual & $3.80(10.07)$ & 0.0 & 31 & 0 \\
\hline Vocational intervention & $8.63(9.22)$ & 5.0 & 26 & 0 \\
\hline \multicolumn{5}{|l|}{ Mann-Whitney U-test: $Z=-2.52, P=0.021$} \\
\hline \multicolumn{5}{|l|}{ Hours worked per week, $n^{a}$} \\
\hline Treatment as usual & $22.50(10.61)$ & 22.50 & 30.00 & 15.00 \\
\hline Vocational intervention & 33.90 (15.51) & 38.00 & 60.00 & 6.00 \\
\hline \multicolumn{5}{|l|}{ Mann-Whitney U-test: $Z=-2.957, P=0.006$} \\
\hline \multicolumn{5}{|l|}{ Pay, AU\$ } \\
\hline Treatment as usual & 3615 (12 473) & 0 & 48370 & 0 \\
\hline Vocational intervention & $4449(5067)$ & 2432 & 14166 & 0 \\
\hline \multicolumn{5}{|l|}{ Mann-Whitney U-test: $Z=-2.279, P=0.012$} \\
\hline \multicolumn{5}{|l|}{ Pay per hour, AU\$ ${ }^{a}$} \\
\hline Treatment as usual & $18.00(4.24)$ & 18.00 & 21.00 & 15.00 \\
\hline Vocational intervention & $16.60(5.86)$ & 15.00 & 30.00 & 8.30 \\
\hline Mann-Whitney U-test: $Z=-2.705, P=0.013$ & & & & \\
\hline
\end{tabular}


A post hoc correlation analysis showed that within groups there were significant one-tailed bivariate correlations between SOFAS score and employment-only outcome in both the intervention $(P=0.004, r=0.58)$ and TAU $(P=0.022, r=0.49)$ groups. There was a correlation between SOFAS score and employment or enrolment outcome only in the TAU group $(P=0.024, r=0.49)$. It makes sense that there would be no correlation in the intervention group on this measure, as $85 \%$ had a successful outcome.

\section{Discussion}

\section{Need for vocational interventions in psychotic illness}

Unemployment and lost productivity is the largest contributor to the indirect costs of psychotic illnesses. ${ }^{18}$ Australian data show that of a total economic cost of schizophrenia to the community of AU\$1.8 billion in 2001, AU\$800 million were associated with unemployment. ${ }^{19}$ In the USA, the costs associated with unemployment of people with schizophrenia in 2002 have been estimated at US\$32.4 billion or $52 \%$ of all schizophrenia-related costs. ${ }^{3}$ Similar figures have been found in European data. ${ }^{20,21}$ An intervention which can harness the desire of people with psychotic illness to work would be of enormous benefit at the level of both the individual and the community in terms of saving money.

\section{Potential advantages of vocational intervention in first-episode psychosis}

To date nearly all of the research on vocational intervention for psychotic illness has been conducted in people with long-standing illness. However, although unemployment is a major problem for those with long-standing psychotic illnesses, people with firstepisode psychosis also have high levels of unemployment. A report on the state of Australian youth showed that among 15- to 24year-olds unemployment was approximately $5 \% .{ }^{22}$ Unemployment in studies of first-episode psychosis populations is 10 times higher (about 40-50\%) than for their same-age peers in the general community. ${ }^{1}$ The phase in life when psychosis tends to have its onset is also the period in which vocational development (the completion of education and starting work) occurs. Thus, it may be argued that vocational skills not developed at this lateadolescence/early-adulthood phase of life presage greater levels of unemployment, especially if a person's psychotic illness develops to a more chronic stage. ${ }^{23}$ Further, there is evidence that unemployment is a risk factor for the development or exacerbation of mental illness ${ }^{24}$ and the misuse of substances. ${ }^{25}$ Finally, it is known that peak levels of disability develop during the early phases of psychotic illness ${ }^{26}$ and efforts made in these phases can ameliorate if not prevent disability. ${ }^{27}$ The most effective earlyintervention programmes are known to reduce the duration of untreated illness from well over a year to only a few months. ${ }^{28}$ Vocational intervention at this time has tremendous potential not only to provide short-term employment experience and skills, but also to prevent development of long-term unemployment and its associated personal, economic and health costs. Therefore, it would seem opportune to implement vocational interventions in the early phases of mental illness. Another advantage of intervention at this stage is that often those with illness are not yet accessing welfare benefits, which have been shown to pose a substantial barrier to participation in the workforce. ${ }^{29}$ Even where they are, the results from our study showed that the median earned (AU\$2432) over 5 weeks was more than would have been received on any Australian government welfare benefit payment over the same period (AU\$476-1138 depending on age and benefit type).

\section{Current study}

This study found that compared with TAU, even where that included referral to external employment agencies, there was a significant advantage to a vocational intervention for young people with first-episode psychosis co-located with their clinical service. This advantage was evident in that those in the intervention group obtained more jobs, worked more hours, earned more money and lasted longer in their jobs than those in the TAU group. Further, the jobs that these participants were successful in acquiring covered a wide range of occupations that were congruent with their own interests and needs.

It is notable that the intervention was enthusiastically received by participants, as evidenced by the $0 \%$ refusal rate. This carried through to a low drop-out rate for those in the intervention group. The higher drop-out rate in the TAU group is not surprising in that people were participating wanting help to find work and were not receiving it. It is a testament to the generosity of the participants in the TAU group that so many stayed in the trial. In future studies, a control condition which offers this group some assistance may be of benefit.

Another factor that possibly contributed to the success of the vocational intervention was the intensity of the intervention. The employment consultant in this trial, in keeping with the IPS model, was limited to a case-load of 20 individuals. This allowed her to provide intensive assistance to participants in their search for work. In comparison, those in the employment sector regularly have case-loads of over 100 and this necessarily limits the intensity of the service they can provide, particularly to those who may need more assistance and support.

\section{Implications of this study}

Employment rehabilitation is not traditionally seen to be part of mental health services. There are many reasons which suggest that it should be. The effects of unemployment on individuals with psychotic illness, which include social marginalisation, higher risk of exacerbation and relapse, lack of role and inability to participate in the economy, have been well-documented. Likewise, unemployment has been demonstrated to compete with direct treatment costs as the largest cost associated with schizophrenia. The results of this study suggest that vocational interventions co-located with and delivered as part of a complete approach to symptomatic and functional recovery are not only desired by people with mental illness, but produce effective vocational outcomes.

Instead of being part of the mental health system, vocational services are often external agencies to which patients are referred by case managers. A second implication of these results is the failure of the current employment system to adequately assist those with mental illness to gain access to paid employment. In Australia, agencies in the employment system often engage in a long, motivation-sapping assessment phase before job searching commences. In addition, if employment is obtained, the outcome payment system for these agencies is predicated on maintaining a person in a job for 3 and 6 months. This is not always applicable to young people who may have little or no work history, and who may wish to explore different work options. The IPS approach has the flexibility to support 'vocational exploration'. Employment systems vary in different countries and economies, but there is no government-level system that we are aware of that is effectively addressing the issue of employment of people with mental illness. As a disability group, people with mental illnesses are consistently overrepresented among the unemployed and welfare recipients. ${ }^{1,8}$

Despite the will of people with mental illness to work, and despite the presence of agencies intended to help them find work, 
in high-income societies there are still high unemployment rates among those with psychotic illness. These facts, combined with the results of this study, suggest that a co-located, early-intervention approach to vocational rehabilitation may be a better bet for governments and individuals than brokered employment services.

\section{Limitations}

This study had a small sample size and only allows preliminary conclusions to be drawn about the employment outcomes. The sample size does not provide sufficient power to examine other potentially important questions such as the impact employment has on symptoms and health system usage or the economic benefits of this intervention. Further, as there is no follow-up at this stage it is not possible to determine whether a short 6-month intervention is sufficient to lead to lasting gains in employment and employment skills. Although the jobs that participants acquired in the course of the project represent a reasonable crosssection, the courses that most participants completed were short and targeted towards specific jobs (e.g. the responsible service of alcohol course was a requirement for working in licensed premises) rather than teaching broader skills (e.g. the secondary English course). Many studies in first-episode psychosis have a majority of males, but our population in both groups was $80 \%$ male. We are unsure of the reasons for this. There may be cultural reasons prompting young males to seek work more than young females. It may also be that case managers prioritise work for males to a greater extent than they do for females. A further limitation of this study is that it lacked an economic analysis of the cost-benefit of the intervention.

This study shows that employment outcomes can be achieved; future work will need to analyse the economic benefit of this intervention in this population over normal employment methodologies.

Eóin Killackey, DPsych, Department of Psychology, School of Behavioural Science, The University of Melbourne, and ORYGEN Research Centre, Parkville; Henry J. Jackson, PhD, Department of Psychology, School of Behavioural Science, The University of Melbourne; Patrick D. McGorry, MD, ORYGEN Research Centre, Parkville, and Department of Psychiatry, The University of Melbourne, Australia

Correspondence: Dr Eóin Killackey, ORYGEN Research Centre, 35 Poplar Road Parkville, Victoria 3052, Australia. E-mail: eoin@unimelb.edu.au

First received 18 Jul 2007, final revision 17 Feb 2008, accepted 13 Mar 2008

\section{References}

1 Killackey EJ, Jackson HJ, Gleeson J, Hickie IB, MCGorry PD. Exciting career opportunity beckons! Early intervention and vocational rehabilitation in first episode psychosis: employing cautious optimism. Aust N Z J Psychiatry 2006; 40: 951-62.

2 Secker J, Grove B, Seebohm P. Challenging barriers to employment, training and education for mental health service users: the service user's perspective. J Ment Health 2001; 10: 395-404.

3 Wu EQ, Birnbaum HG, Shi L, Ball DE, Kessler RC, Moulis M, Aggarwal J. The economic burden of schizophrenia in the United States in 2002. J Clin Psychiatry 2005; 66: 1122-9.

4 Carr V, Lewin TJ, Neil AL. What is the value of treating schizophrenia? Aust N Z J Psychiatry 2006; 40: 963-71.
5 Crowther RE, Marshall M, Bond GR, Huxley P. Vocational rehabilitation for people with severe mental illness. Cochrane Database Syst Rev 2001; (2): CD003080.

6 Becker DR, Drake RE. A Working Life For People With Severe Mental Illness. Oxford University Press, 2003.

7 Bond GR. Supported employment: evidence for an evidence-based practice. Psychiatr Rehabil J 2004; 27: 345-59.

8 Turton N. Welfare benefits and work disincentives. J Ment Health 2001; 10 285-300.

9 Killackey E, Waghorn G. The challenge of integrating employment services with public mental health services in Australia: progress at the first demonstration site. Psychiatr Rehabil $J$ in press.

10 Ventura J, Lukoff D, Nuechterlein KH, Liberman RP, Green MF, Shaner A. Brief Psychiatric Rating Scale (BPRS) Expanded Version (4.0). Scales, Anchor Points, and Administration Manual. UCLA Department of Psychiatry and Behavioral Sciences, 1993.

11 Andreasen NC. Scale for Assessment of Negative Symptoms (SANS). University of lowa, 1984.

12 Eaton Ww. Centre for Epidemiologic Studies Depression Scale - Revised (CESD-R). In Innovations in Clinical Practice: A Source Book (eds L VandeCreek, T Jackson): 295-7. Professional Resource Exchange, 2001.

13 First MB, Spitzer RL, Gibbon M, Williams JBW. Structured Clinical Interview for DSM-IV-TR Axis I Disorders, Research Version, Patient Edition (SCID-I/P). Biometrics Research, New York State Psychiatric Institute, 2001.

14 Heinrichs DW, Hanlon TE, Carpenter WT. The Quality of Life Scale: an instrument for rating the schizophrenic deficit syndrome. Schizophr Bull 1984; 10: 388-98.

15 American Psychiatric Association. Diagnostic and Statistical Manual of Mental Disorders (4th edn) (DSM-IV). American Psychiatric Association, 1994.

16 Becker DR, Smith J, Tanzman B, Drake RE, Tremblay T. Fidelity of supported employment programs and employment outcomes. Psychiatr Serv 2001; 52: 834-6.

17 Jenkins R, Lewis $G$, Bebbington $P$, Brugha $T$, Farrell M, Gill B, Meltzer $H$. The national psychiatric morbidity surveys of Great Britain - initial findings from the Household Survey. Int Rev Psychiatry 2003; 15: 29-42.

18 Knapp M, Mangalore R, Simon J. The global costs of schizophrenia. Schizophr Bull 2004; 30: 279-93.

19 SANE Australia. Schizophrenia: Costs. An Analysis of the Burden of Schizophrenia and Related Suicide in Australia. SANE Australia, 2002.

20 Andlin-Sobocki P, Rössler W. Cost of psychotic disorders in Europe. Eur J Neurol 2005; 12: 74-7.

21 Löthgren M. Economic evidence in psychotic disorders: a review. Eur $\mathrm{J}$ Health Econ 2004; 5 (suppl 1): s67-74.

22 Long M. How Young People are Faring: Key Indicators 2005. Dusseldorp Skills Forum, 2005

23 McGorry PD, Hickie IB, Yung AR, Pantelis C, Jackson HJ. Clinical staging of psychiatric disorders: a heuristic framework for choosing earlier, safer and more effective interventions. Aust N Z J Psychiatry 2006; 40: 616-22.

24 Dooley D. Unemployment, underemployment and mental health conceptualizing employment status as a continuum. Am J Community Psychol 2003; 32: 9-20.

25 Mitchell DP, Betts A, Epling M. Youth employment, mental health and substance misuse: a challenge to mental health services. J Psychiatr Ment Health Nurs 2002; 9: 191-8.

26 Birchwood M, Fiorillo A. The critical period for early intervention. Psychiatr Rehabil Skills 2000; 4: 182-98.

27 McGorry P. 'Every me and every you': responding to the hidden challenge of mental illness in Australia. Australas Psychiatry 2005; 13: 3-15.

28 Killackey E, Yung AR. Effectiveness of early intervention in psychosis. Curr Opin Psychiatry 2007; 20: 121-5.

29 Rosenheck R, Leslie D, Keefe R, McEvoy J, Swartz M, Perkins D, Stroup S, Hsiao JK, Lieberman J; CATIE Study Investigators Group. Barriers to employment for people with schizophrenia. Am J Psychiatry 2006; 163: $411-7$. 